\title{
Soluble guanylyl cyclase activators increase the expression of tolerance to morphine analgesic effect
}

\author{
Durmus $\mathrm{N}^{1}$, Bagcivan $\mathrm{I}^{2}$, Ozdemir $\mathrm{E}^{3}$, Altun $\mathrm{A}^{2}$, Gursoy $\mathrm{S}^{4}$ \\ Department of Medical Pharmacology, Hacettepe University School of Medicine, Ankara, Turkey. \\ drnedimdurmus@gmail.com
}

\begin{abstract}
Objectives: It is aimed to investigate the effects of guanylyl cyclase activation and inhibition on acute morphine antinociception and the development of tolerance to its effect.

Background: Nitric oxide-soluble guanylyl cyclase signal transduction cascade suggested to play an important role in the development of tolerance to antinociceptive effects of morphine.

Methods: Nociception was evaluated by tail flick and hot plate tests in male Wistar rats. The analgesic effects of intraperitoneal protoporphyrin IX (PPIX; an activator of soluble guanylyl cyclase), 3-morpholinosydnonimine hydrochloride (SIN-1; NO donor and activator of guanylyl cyclase), S-Nitroso-N-acetylpenicillamine (SNAP; an activator of guanylyl cyclase), 3,3-Bis (amino ethyl)-1-hydroxy-2-oxo-1-triazene (NOC-18; NO donor activating guanylyl cyclase) and $1 \mathrm{H}$-[1,2,4]oxadiazolo[4,3-a]quinoxalin-1-one (ODQ; an inhibitor of guanylyl cyclase) alone or in combination with subcutaneous morphine injection were evaluated. Their effects on morphine tolerance development were evaluated by giving these agents 20 minutes prior to twice daily morphine injection during tolerance development for 5 days. On day 6 , the expression of morphine tolerance was determined.

Results: PPIX, SIN-1, SNAP and NOC-18 significantly increased expression of morphine tolerance while ODQ decreased.

Conclusion: These data suggested that SGC activators have a significant role in tolerance to the analgesic effect of morphine (Tab. 1, Fig. 4, Ref. 29). Text in PDF www.elis.sk.

Key words: analgesia, morphine tolerance, soluble guanylyl cyclase.
\end{abstract}

Morphine and other opioid drugs are widely used for the treatment of moderate to severe intensity pain. However, tolerance development to the antinociceptive effects of opioids continue to be a significant clinical problem. Although a variety of agents including N-methyl-d-aspartate (NMDA) antagonists, nitric oxide synthase (NOS) inhibitors, calcium channel blockers, kinase inhibitors, and cyclooxygenase inhibitors $(1,2)$ suggested to block the development of tolerance to the antinociceptive tolerance to opioids, the physiological and biochemical mechanisms underlying the development of tolerance are still unclear (3-5).

Nitric oxide (NO) is synthesized from L-arginine and oxygen by the NOS enzyme. After production, NO rapidly diffuses across cell membranes and binds to the heme cofactor of guanylyl cyclase (sGC). sGC forms a stable complex with NO leading to significant

${ }^{1}$ Department of Medical Pharmacology, Hacettepe University School of Medicine, Ankara, Turkey, ${ }^{2}$ Departments of Pharmacology, Cumhuriyet University School of Medicine, Sivas, Turkey, ${ }^{3}$ Department of Physiology Cumhuriyet University School of Medicine, Sivas, Turkey, and ${ }^{4}$ Department of Anesthesiology and Reanimation, Cumhuriyet University School of Medicine, Sivas, Turkey

Address for correspondence: N. Durmus, MD, Department of Medical Pharmacology, Hacettepe University School of Medicine, 06100 Sihhiye/ /Ankara, Turkey

Phone: +90.312.2183104, Fax: +90.321.2183114

Acknowledgements: This work was supported by the Cumhuriyet University Scientific Research Project Unit, Sivas, Turkey (Grant Number T-329). increases in cyclic guanosine monophosphate (cGMP) levels that directly modulate phosphodiesterases, ion gated channels, or cGMP-dependent protein kinases which in turn regulate the physiological functions $(6,7)$. Most of the in vivo studies evaluating the relation between morphine and nitric oxide (NO) have focused on the effects of NOS inhibitors, NMDA receptor antagonists or exogenous administration of L-arginine. However the effects of sGC activators or sGC inhibitors on the pharmacodynamics of morphine are unclear. In this study, we aimed to examine the antinociceptive effects of sGC activators and inhibitors and their role on the development of morphine tolerance in rats.

\section{Methods}

\section{Drug preparation}

Protoporphyrin IX (PPIX; an activator of sGC), 3-morpholinosydnonimine hydrochloride (SIN-1; NO donor and activator of sGC) and 3,3-Bis (amino ethyl)-1-hydroxy-2-oxo-1-triazene (NOC-18; NO donor, activator of sGC) (purchased from SigmaAldrich, USA) and morphine sulphate (obtained from Cumhuriyet University Hospital, Turkey) were dissolved in $0.9 \%$ saline. ODQ $(1 \mathrm{H}-[1,2,4]$ oxadiazolo[4,3-a]quinoxalin-1-one) (an inhibitor of sGC) was purchased from Sigma-Aldrich, USA and dissolved in $100 \%$ dimethyl sulfoxide. Solutions were freshly prepared on the day of experiment. All of the drugs were given intraperitoneally (i.p.) in a volume of $1 \mathrm{ml} / \mathrm{kg}$. 
Animals

The adult male Wistar albino rats weighing 185-215 g were used. Animals were housed in a temperature-controlled facility of $23 \pm 2{ }^{\circ} \mathrm{C}$, under 12 -h light/dark cycle (7 a.m. to 7 p.m.) and with free access to water and food. The procedures were approved by the Cumhuriyet University Animal Ethics Committee, and conducted in accordance with the recommendations of the Guide for the Care and Use of Laboratory Animals.

\section{Analgesia tests}

In tail flick test, we used a standardized tail flick apparatus (May TF 0703 Tail-flick Unit). The radiant heat source was focused on the distal portion of the tail at $3 \mathrm{~cm}$ after administration of drugs or vehicle. The cut-off latency was set at $15 \mathrm{~s}$ to avoid tissue damage. Following vehicle or compound administration, tail-flick latencies (TFL) were obtained. In hot plate test, animals were individually placed on a hot-plate (May AHP 0603 Analgesic Hot-plate) with the temperature adjusted to $54 \pm 2{ }^{\circ} \mathrm{C}$. The latency to the first sign of paw licking or jump response to avoid the heat was taken as an index of the pain threshold. The cut-off time was $60 \mathrm{~s}$ in order to avoid damage to the paw. TFL and hot plate latencies were measured 10 minutes prior and at 30, 60, 90 and $120 \mathrm{~min}$ after injections.

\section{Experimental protocols}

The effects of single administration of PPIX (20 mg/kg) (8), SIN-1 (2 $\mu \mathrm{g} / \mathrm{kg})(9)$, SNAP $(30 \mu \mathrm{mol} / \mathrm{kg})(10)$, NOC-18 (0,4 mg/ $\mathrm{kg}$; determined by preliminary experiments (data not shown)), ODQ (20 mg/kg) (11) on morphine (2.5, 5 or $7.5 \mathrm{mg} / \mathrm{kg})$-induced analgesic effect were evaluated. For tolerance induction, groups of rats were randomly chosen and morphine was given chronically twice daily at a dose of $20 \mathrm{mg} / \mathrm{kg}$ i.p. from day 1 to 5 . In tolerance treatment group, PPIX (20 mg/kg), SIN-1 (2 $\mu \mathrm{g} / \mathrm{kg})$, SNAP (30 $\mu \mathrm{mol} / \mathrm{kg})$, NOC-18 $(0,4 \mathrm{mg} / \mathrm{kg})$ or ODQ $(20 \mathrm{mg} / \mathrm{kg})$ were injected i.p. 20 min prior to the every morphine administration. To evaluate the treatment effects of study agents on day 6 , after morphine tolerance had developed, the analgesic effects of the challenge dose of morphine $(5 \mathrm{mg} / \mathrm{kg}$; s.c.) were measured 3 hours after the last morphine injection. In the saline-treated group, animals received only saline $(1 \mathrm{ml} / \mathrm{kg})$ instead of morphine during the induction session.

The analgesic effects of PPIX, SIN-1, SNAP, NOC-18 and morphine were considered at 30-min intervals $(0,30,60,90$ and $120 \mathrm{~min})$ by tail-flick and hot-plate test in rats $(\mathrm{n}=6$ in each group) on day 1 . In the saline-treated group, animals received saline $(10 \mathrm{ml} / \mathrm{kg})$ instead of morphine during the induction session. In addition, all agents were given in that volume intraperitoneally (i.p.).

\section{Data analysis}

In order to calculate the rate of maximal antinociceptive effects (\% MPE), tail-flick and hot-plate latencies were converted to percentage of antinociceptive effect using the following equation:

$\% \mathrm{MPE}=[($ test latency-baseline $) /($ cut off-baseline $)] \times 100$.

The \% MPE was calculated separately for each rat based on single baseline score. The baseline latency was measured for each rat. The baseline latencies were approximately $2.7-3.2 \mathrm{~s}$ in all rats. Animals with a baseline latency below 2.7 or above $3.2 \mathrm{~s}$ were excluded from further testing.

\section{Statistical analysis}

The effect of antinociception was measured and the mean of $\%$ MPEs in all groups was calculated. All experimental results were expressed as mean \pm SEM (standard error of mean). In all cases, the criterion for statistical significance was $\mathrm{p}<0.05$. The data were analysed by analysis of variance followed by Tukey test using the computer program SPSS (version 15.0 for Windows).
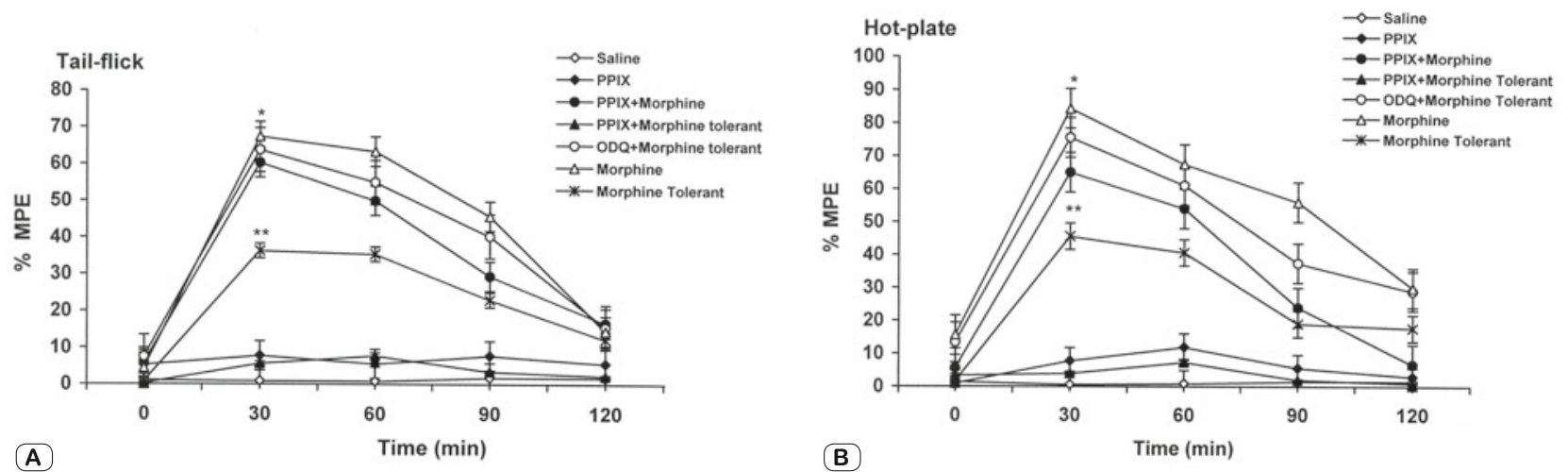

Fig. 1. Effects of protoporphyrin IX (PPIX, activator of sGC) on the expression of morphine tolerance. (A) shows effect of PPIX (20 mg/kg) in the tail-flick test, and (B) shows effect of PPIX in the hot-plate test. Pretreatment of morphine tolerant animals with PPIX significantly decreased \% MPE (increase tolerance to morphine) in both tail-flick $(p<0.05$; Figure A) and hot-plate tests $(p<0.05$; Figure B) compared with morphine-tolerant animals. However, ODQ (inhibitor of sGC) significantly decreased the expression of tolerance to morphine antinociceptive effect in tail-flick $(p<0.05$; Figure $A)$ and hot-plate tests $(p<0.05$; Figure B). Each point represents the mean \pm SEM of percent of maximal possible effect (\% MPE) for 6 rats. $* p<0.01$ and $* * p<0.05$ compared to saline-treated group. 

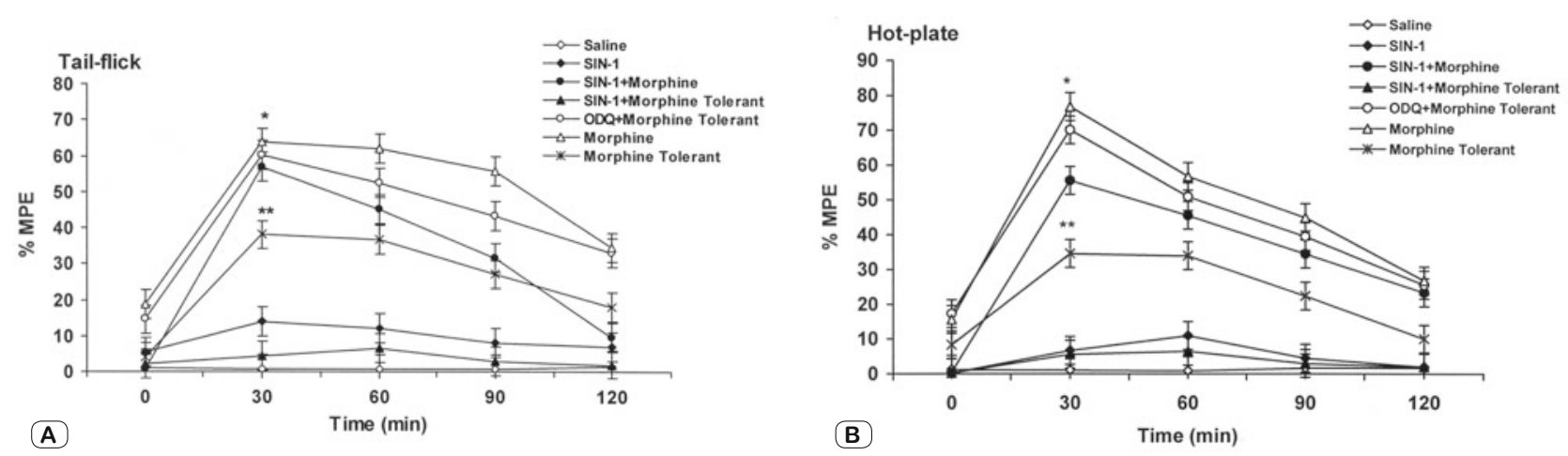

Fig. 2. Effects of 3-morpholinosydnonimine hydrochloride (SIN-1) on the expression of morphine tolerance. (A) shows effect of SIN-1 (2 $\mu \mathrm{g} / \mathrm{kg}$ ip) in the tail-flick test, and (B) shows effect of SIN-1 in the hot-plate test. Pretreatment of morphine-tolerant animals with SIN-1 significantly decreased the \% MPE in both tail-flick $(p<0.05$; Figure $A)$ and hot-plate tests $(p<0.05$; Figure B). Each point represents the mean \pm SEM of percent of maximal possible effect (\% MPE) for 6 rats. * $p<0.01$ and $* * p<0.05$ compared to saline-treated group.
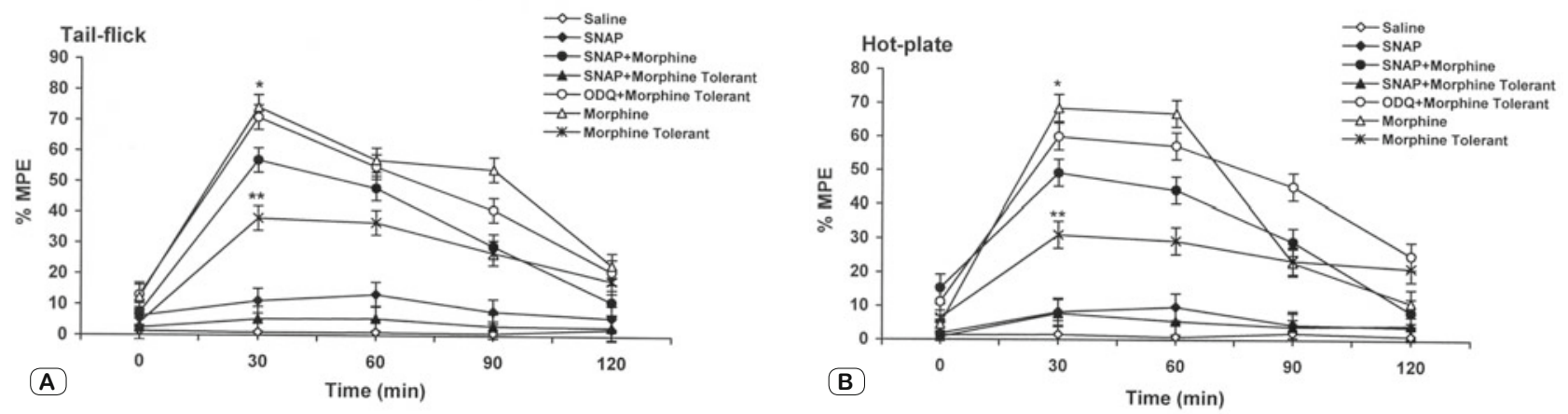

Fig. 3. Effects of S-Nitroso-N-acetyl-DL-penicillamine (SNAP) on the expression of morphine tolerance. (A) shows effect of SNAP (30 $\mu \mathrm{mol} / \mathrm{kg}$; i.p.) in the tail-flick test, and (B) shows effect of SNAP in the hot-plate test. Pretreatment of morphine tolerant animals with SNAP significantly decreased the \% MPE in both tail-flick $(p<0.05$; Figure $A)$ and hot-plate test $(p<0.05$; Figure B). Each point represents the mean \pm SEM of percent of maximal possible effect (\% MPE) for 6 rats. * $p<0.01$ and $* * p<0.05$ compared to saline-treated group.

\section{Results}

\section{Effects of PPIX on morphine antinociception and tolerance}

PPIX (activator of sGC) significantly increased the expression of tolerance to morphine antinociceptive effect, as indicated by the decrease in \% MPE in the PPIX treatment morphine tolerant groups in both tail-flick $(\mathrm{p}<0.05)$ (Fig. 1A) and hot-plate tests $(\mathrm{p}<0.05)$ (Fig. 1B) compared to morphine tolerant groups. However, pretreatment of animals with ODQ (inhibitor of sGC) significantly decreased the expression of tolerance to morphine antinociceptive effect in analgesia tests $(\mathrm{p}<0.01)$ (Figs $1 \mathrm{~A}$ and 1B) compared to morphine tolerant group. PPIX also decreased analgesic effect of morphine in the analgesia tests, but this difference was not statistically significant between two groups. The peak values of this group were observed at 30 min after administration of morphine in both tail-flick and hot-plate tests $(67.5 \pm 5.1$ and $84.4 \pm 4.6$ respectively).

\section{Effects of SIN-1 on morphine antinociception and tolerance}

Pretreatment of animals with SIN-1 significantly increased the expression of tolerance to morphine antinociceptive effect in both tail-flick ( $\mathrm{p}<0.05)$ (Fig. $2 \mathrm{~A})$ and hot-plate tests $(\mathrm{p}<0.05)$ (Fig. 2B) compared to morphine tolerant groups. These figures also suggested that ODQ significantly decreased the expression of tolerance to morphine antinociceptive effect in analgesia tests ( $p<0.01$ ) (Figs 2A and 2B) compared to morphine tolerant group. Similar to PPIX, the peak value of these group were observed at 30 min after administration of morphine in both tail-flick and hotplate test $(63.7 \pm 4.8$ and $76.8 \pm 5.6$ respectively $)$.

\section{Effects of SNAP on morphine antinociception and tolerance}

Administration of SNAP significantly decreased the \% MPE in the morphine tolerant groups in both tail-flick $(\mathrm{p}<0.05)$ (Fig. $3 \mathrm{~A})$ and hot-plate tests $(\mathrm{p}<0.05)$ (Fig. 3B) compared to morphine tolerant groups. Namely, SNAP significantly increased the expression of tolerance to morphine analgesic effect. The peak values of this group were observed at 30 min after administration of morphine in both tail-flick and hot-plate tests $(74.3 \pm 4.7$ and $68.5 \pm 4.3$ respectively).

Effects of NOC-18 on morphine antinociception and tolerance NOC-18 (a nitric oxide donor, activator of sGC) significantly 


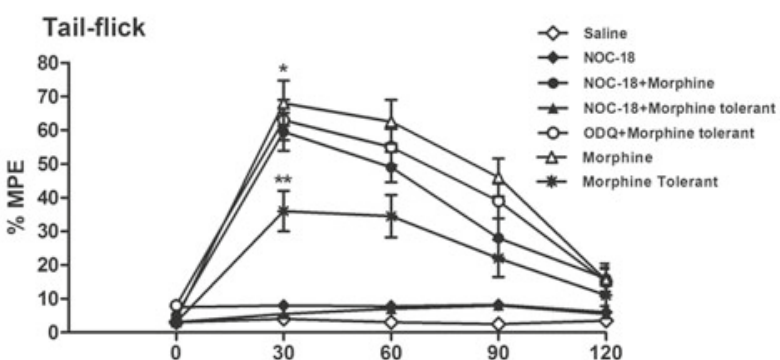

(A)

Time (min)

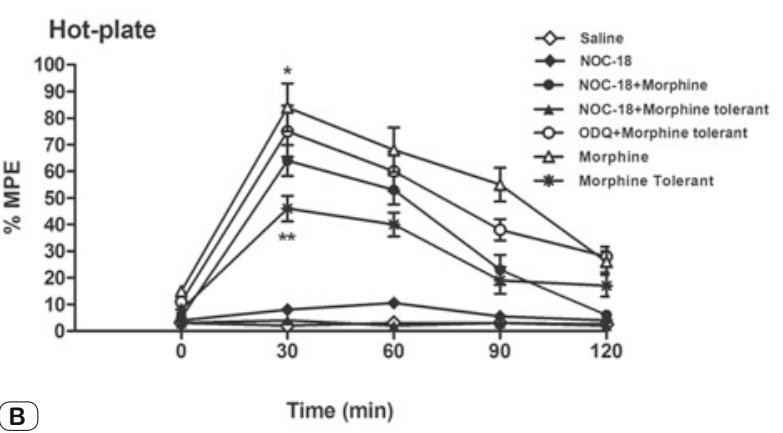

Fig. 4. Effects of 3,3-Bis (amino ethyl)-1-hydroxy-2-oxo-1-triazene (NOC-18; NO donor, activator of sGC) on the expression of morphine tolerance. (A) shows effect of NOC-18 ((0.4 mg/kg; i.p.) in the tail-flick test, and (B) shows effect of NOC-18 in the hot-plate test. Pretreatment of morphine-tolerant animals with NOC-18 significantly decreased the $\%$ MPE in both tail-flick $(p<0.05$; Figure A) and hot-plate tests $(p<$ 0.05 ; Figure B). Each point represents the mean \pm SEM of percent of maximal possible effect $(\%$ MPE) for 6 rats. $* p<0.01$ and $* * p<0.05$ compared to saline-treated group.

increased the expression of tolerance to morphine antinociceptive effect, as indicated by the decrease in \% MPE in the NOC18 treatment morphine tolerant groups in both tail-flick $(\mathrm{p}<0.05)$ (Fig. 4A) and hot-plate tests $(\mathrm{p}<0.05)$ (Fig. 1B) compared to morphine tolerant groups. However, inhibition of sGC by ODQ significantly decreased the expression of tolerance to morphine antinociceptive effect in both analgesia tests $(\mathrm{p}<0.01)$ (Fig. 3A and $3 \mathrm{~B}$ ) compared to morphine tolerant group. NOC-18 also decreased the analgesic effect of morphine in the analgesia tests, but this difference was not statistically significant between two groups. Like all other activator agents the peak values of these groups were observed at 30 min after administration of morphine in both tail-flick and hot-plate tests $(63.1 \pm 6.2$ and $68.2 \pm 6.7$ respectively).

\section{The analgesic effects of different doses of morphine}

For the determination of effective morphine dose, the antinociceptive response was measured for three different doses of morphine $(2.5,5$ and $7.5 \mathrm{mg} / \mathrm{kg}$; s.c.) at 30 -min intervals $(0,30,60$, $90,120)$ by tail-flick and hot-plate tests. The maximum \% MPE was observed at $30 \mathrm{~min}$ after the administration of a $5 \mathrm{mg} / \mathrm{kg}$ dose of morphine ( $74.3 \pm 9.0$ for tail-flick test and $64.1 \pm 8.9$ for hot-plate test) (Tab. 1). The \% MPE produced by morphine $(5 \mathrm{mg} / \mathrm{kg})$ was significantly higher than in the other groups $(2.5 \mathrm{mg} / \mathrm{kg}$ morphine and saline group) in both tail-flick test $(\mathrm{p}<0.05)$ and hot-plate test $(\mathrm{p}<0.05)$ in rats.

\section{Discussion}

The link between opioid analgesia and NO has been suggested for many years and it has been reported that NO-cGMP signal pathways play an important role in the opioid analgesia. However, the role of sGC activators on the development of tolerance to morphine analgesic effect is not clear. In the present study, it is observed that PPIX, SIN-1, SNAP and NOC-18 (activators of sGC) significantly increased the expression of tolerance to morphine antinociceptive effect. In addition to this, administration of ODQ (inhibitor of sGC) decreased the development of tolerance to morphine in morphine-tolerant rats.

Despite a great deal of research, the neurobiological mechanisms of the development of opioid tolerance and dependence are only partially understood. Several researchers suggested that different mechanisms participate in the development of morphine tolerance (12-14). Opioid receptor downregulation, alterations in binding of the peptide to the receptor, upregulation of cAMP pathway, alterations in signal transduction cascades, and possible

Tab. 1. The analgesic effects of different doses of morphine.

\begin{tabular}{|c|c|c|c|c|c|}
\hline Time (minutes) & 0 & 30 & 60 & 90 & 120 \\
\hline \multicolumn{6}{|l|}{ Tail-flick } \\
\hline Saline & $3.1 \pm 0.8$ & $4.1 \pm 0.9$ & $3.7 \pm 0.6$ & $3.9 \pm 1.1$ & $3.6 \pm 0.9$ \\
\hline Morphine $(2.5 \mathrm{mg} / \mathrm{kg})$ & $5.1 \pm 0.8$ & $39.1 \pm 7.8$ & $32.3 \pm 5.2$ & $15.4 \pm 3.5$ & $9.4 \pm 1.8$ \\
\hline Morphine $(5 \mathrm{mg} / \mathrm{kg})$ & $6.3 \pm 0.9$ & $74.3 \pm 9.0 *$ & $66.8 \pm 6.3$ & $46.1 \pm 5.8$ & $24.4 \pm 6.2$ \\
\hline Morphine $(7.5 \mathrm{mg} / \mathrm{kg})$ & $4.6 \pm 1.2$ & $64.3 \pm 6.1$ & $59.5 \pm 7.3$ & $38.5 \pm 3.8$ & $21.5 \pm 5.3$ \\
\hline \multicolumn{6}{|l|}{ Hot-plate } \\
\hline Saline & $4.6 \pm 0.5$ & $6.2 \pm 0.9$ & $5.1 \pm 0.8$ & $5.6 \pm 0.8$ & $4.8 \pm 0.9$ \\
\hline Morphine $(2.5 \mathrm{mg} / \mathrm{kg})$ & $7.9 \pm 1.4$ & $35.4 \pm 6.1$ & $24.9 \pm 6.2$ & $22.8 \pm 5.6$ & $18.4 \pm 5.2$ \\
\hline Morphine $(5 \mathrm{mg} / \mathrm{kg})$ & $9.6 \pm 1.5$ & $64.1 \pm 8.9^{*}$ & $56.5 \pm 6.3$ & $51.2 \pm 7.5$ & $32.4 \pm 4.0$ \\
\hline Morphine $(7.5 \mathrm{mg} / \mathrm{kg})$ & $7.4 \pm 1.1$ & $51.2 \pm 5.4$ & $7.3 \pm 8.2$ & $41.5 \pm 4.3$ & $27.8 \pm 8.0$ \\
\hline
\end{tabular}

Data are means \pm S.E.M. ${ }^{*} \mathrm{p}<0.05$ as compared with its saline $(\mathrm{n}=6$ in each group). 
changes in drug disposition to the receptor site are the suggested prominent mechanisms (15-18). In addition to these molecular changes, a wide range of neurotransmitters or neuromodulators, including serotonin, noradrenaline, dopamine, cholecystokinin, GABA, agmatine, adenosine, and NO have been shown to play different roles in the mechanisms of tolerance and dependence development to opioid analgesics $(19,20)$. It has been suggested that morphine reduces presynaptic neurotransmitter release such as glutamate, and thus lowers the amount of glutamate available for the NMDA receptors. Injection of L-NAME also reduces NO concentrations and thus decreases secondarily the extracellular concentrations of primary afferent neurotransmitter glutamate. Both of them would lead to attenuation of pain (21). It has been also demostrated that inhibition of NO synthase attenuates the NMDA receptor-mediated synaptic transmission of nociception inputs (22) and consequently, it may enhance the opioid antinociception (23).

Modulation of the functions of endogenous substances appears to be very important in the induction and expression of morphine tolerance and dependence. Among these non-opioid systems, NO seems to play a key role in opioid tolerance and dependence $(15,24,25)$. NO is widely recognized as an intercellular messenger that plays important roles in the regulation of physiological functions. NO is formed intracellularly through the action of nitric acid synthase (NOS). NOS has three classified isoforms including neuronal (nNOS), inducible (iNOS), and endothelial (eNOS). The activity of constitutive isoforms, including nNOS and eNOS, is controlled by intracellular calcium, which in turn is regulated by excitatory amino acids interacting with the NMDA receptor. The inducible isoform, on the other hand, is not regulated by calcium. L-Arginine, the only known substrate of all isoforms of NOS, is oxidized to form NO and L-citrulline (26). The activation of NOS and release of NO stimulates the sGC, which result in an increase in cyclic GMP levels within the target cell $(6,27)$. Xu et al $(28)$ suggested that methylene blue and LY83,583 (sGC inhibitors) decreased the development of morphine tolerance. In the present study, we found that ODQ (inhibitor of sGC) decreased the development of tolerance to morphine. These obtained data demonstrate that the NO-sGC system may participate in the mediation of morphine tolerance. The mechanisms involved in the effect of $\mathrm{NO}$ on the development of tolerance may be both dependent on and independed of cyclic GMP. Indeed, NO has been demonstrated to modulate certain neuronal proteins through a cyclic GMP-independent process. For example, Hess et al (29) reported that exogenous and endogenously generated NO resulted in modification of cysteine residues on neuronal proteins. In particular, the exposure of synaptosomes to NO inhibited the subsequent thiol-linked ADP-ribosylation of the heterotrimeric G-protein by pertussis toxin.

In conclusion, opioid tolerance is a complex phenomenon that involves one or more of several purported mechanisms including opioid receptor downregulation, alterations in binding of the peptide to the receptor, modulation of G-protein-coupled receptor activation, alterations of downstream receptor processes, and possible changes in drug disposition to the receptor site.
While the intricacies of this process have yet to be elucidated, the data presented herein suggest a major role of NO-sGC in modulating the loss of antinociceptive effect during prolonged morphine administration, and provide an insight into the manner by which sGC activators alters the tolerance to morphine antinociceptive effect.

\section{References}

1. Ossipov MH, Lai J, Vanderah TW, Porreca F. Induction of pain facilitation by sustained opioid exposure: relationship to opioid antinociceptive tolerance. Life Sci 2003; 73: 783-800.

2. Ossipov, MH, Lai J, King T, Vanderah TW, Malan TP Jr, Hruby VJ, Porreca F. Antinociceptive and nociceptive actions of opioids. J Neurobiol 2004; 61: 126-148.

3. McNally GP. Pain facilitatory circuits in the mammalian central nervous system: their behavioral significance and role in morphine analgesic tolerance. Neurosci Biobehav 1999; 23: 1059-1078.

4. Law PY, Loh HH, Wei LN. Insights into the receptor transcription andsignaling: implications in opioid tolerance and dependence. Neuropharmacology 2004; 47: 300-311.

5. Waldhoer M, Bartlett SE, Whistler JL. Opioid receptors. Annu Rev Biochem 2004; 73: 953-990.

6. Bredt D. S. and Snyder S. H. Nitric oxide, a novel neuronal messenger. Neuron 1992; 8: 3-11.

7. Derbyshire ER, Marletta MA. Structure and Regulation of Soluble Guanylate Cyclase. Annu Rev Biochem 2012; 81: 533-559.

8. Ignarro LJ, Wood KS, Wolin MS. Activation of purified soluble guanylate cyclase by protoporphyrin IX. Proc Natl Acad ScL USA 1982; 79 : 2870-2873.

9. Sousa AM, Prado WA. The dual effect of a nitric oxide donor in nociception. Brain Res 2001; 897: 9-19.

10. Li X, Clark JD. Spinal cord nitric oxide synthase and heme oxygenase limit morphine induced analgesia. Mol Brain Res 2001; 95: 96-102.

11. Cechova S, Pajewski TN. The soluble guanylyl cyclase inhibitor ODQ, 1h-[1,2,4]oxadiazolo[4,3-a]quinoxalin-1-one, dose-dependently reduces the threshold for isoflurane anesthesia in rats. Anesth Analg 2004; 99 : $752-757$.

12. Joharchi K, Jorjani M. The role of nitric oxide in diabetes-induced changes of morphine tolerance in rats. Eur J Pharmacol 2007; 570: 66-71.

13. Morgan MM, Bobeck EN, Ingram SL. Glutamate modulation of antinociception, but not tolerance, produced by morphine microinjection into the periaqueductal gray of the rat. Brain Res 2009; 1295: 59-66.

14. Nayebi AR, Rezazadeh H, Parsal Y. Effect of fluoxetine on tolerance to the analgesic effect of morphine in mice with skin cancer. Pharmal Rep 2009; 61: 453-458.

15. Heinzen EL, Pollack GM. The development of morphine antinociceptive tolerance in nitric oxide synthase-deficient mice. Biochem Pharmacol 2004; 67: 735-741.

16. Koch T, Hollt V. Role of receptor internalization in opioid tolerance and dependence. Pharmacol Ther 2008; 117: 199-206.

17. Liu J, Anand KJS. Protein kinases modulate the cellular adaptations associated with opioid tolerance and dependence. Brain Res Rev 2001; 38: $1-19$. 
18. Taylor DA, Fleming WW. Unifying perspectives in the mechanisms underlying the development of tolerance and physical dependence to opioids. J Pharmacol Exp Ther 2001; 297: 11-18.

19. Bhargava HN. Diversity of agents that modify opioid tolerance, physical dependence, abstinence syndrome and self administrative behavior. Pharmacol Rev 1994; 46: 293-324.

20. Dambisya YM, Lee TL. Role of nitric oxide in the induction and expression of morphine tolerance and dependence in mice. Br J Pharmacol 1996; 117: 914-918.

21. Watanabe C, Okuda K, Sakurada C, Ando R, Sakurada T, Sakurada $S$. Evidence that nitric oxide-glutamate cascade modulates spinal antinociceptive effect of morphine: a behavioural and microdialysis study in rats. Brain Res 2003; 990: 77-86.

22. Malmberg AB, Yaksh TL. Spinal nitric oxide synthesis inhibition blocks NMDA-induced thermal hyperalgesia and produces antinociception in the formalin test in rats. Pain 1993; 54: 291-300.

23. Machelska H, Labuz D, Przewlocki R, Przewlocki B. Inhibition of nitric oxide synthase enhances antinociception mediated by $\mathrm{Mu}$, Delta and Kappa opioid receptors in acute and prolonged pain in the rat spinal cord. J Pharmacol Exp Ther 1997; 282: 977-984.
24. Pasternak GW, Kolesnikov YA, Babey AM. Perspectives on the Nmethyl-D-aspartate/nitric oxide cascade and opioid tolerance. Neuropsychopharmacology 1995; 13: 309-313.

25. Ulugol A, Aslantas A, Karadag HC, Bulbul ED, Tuncer A, Dokmeci I. The effect of combined systemic administration of morphine and L-name, a nitric oxide synthase inhibitor, on behavioral signs of neuropathic pain in rats. Neurosci Res Commun 2002; 30: 143-153.

26. Moncada S, Higgs EA. The L-arginine-nitric oxide pathway. New Engl J Med 1993; 329: 2002-2012.

27. Romero A, Hernandez L, Garcia-Nogales P, Puig MM. Deletion of the inducible nitric oxide synthase gene reduces peripheral morphine tolerance in a mouse model of chronic inflammation. Fund Cli Pharm 2010; 24: 317-323.

28. Xu JY, Hill KP, Bidlack JM. The nitric oxide/cyclic GMP system at the supraspinal site is involved in the development of acute morphine antinociceptive tolerance. J Pharmacol Exp Therap 1998; 284: 196-201.

29. Hess DT, Lin LH, Freeman JA,Norden J J. Modification of cysteine residues with Go and other neuronal proteins by exposure to nitric oxide. Neuropharmacology 1994; 33: 1283-1292.

Received January 30, 2013. Accepted March 8, 2014. 